\title{
Percepção de risco de pessoas envolvidas com intoxicação por chumbo ${ }^{1}$
}

\author{
Lígia Ebner Melchiori² \\ Patrícia Kusumi \\ Olga Maria Piazentin Rolim Rodrigues \\ Tânia Gracy do Valle \\ Vera Lúcia Messias Fialho Capellini \\ Carmem Maria Bueno Neme \\ Universidade Estadual Paulista Júlio de Mesquita Filho, Bauru-SP, Brasil
}

\begin{abstract}
Resumo: Este estudo pretendeu verificar a percepção que as crianças e os seus responsáveis têm sobre a intoxicação por chumbo e quais implicações relatam sobre o fato. Participaram desse estudo 50 crianças intoxicadas, de ambos os sexos, com idade de 4 a 13 anos e seus genitores e/ou responsáveis. Os participantes responderam a entrevistas estruturadas que buscaram investigar o que é o chumbo, como se dá a intoxicação, seus efeitos no organismo infantil, possíveis alterações no ambiente em função da contaminação e, o que os adultos julgam que melhoraria o desenvolvimento das crianças intoxicadas. Os resultados indicaram a falta de compreensão de vários entre os aspectos investigados e a evolução do conhecimento com o aumento da idade. Tais dados poderiam subsidiar a proposição de políticas de saúde pública adequadas e efetivas para o atendimento a essa população, assim como a divulgação de informações corretas sobre o acontecido e seus desdobramentos.
\end{abstract}

Palavras-chave: intoxicação por chumbo, crianças, pais.

\section{Risk perception of people involved with lead poisoning}

\begin{abstract}
This study investigated the perception of children and their parents about lead poisoning and its consequences. A total of 50 male and female children poisoned by lead, ages between 4 and 13 years, and their respective parents and legal guardians participated in the study. The participants answered structured interviews that asked about what lead is, how poisoning occurs and its effects on children's bodies, potential changes in the environment due to poisoning, and what adults believe would improve the development of poisoned children. The results indicate lack of understanding on several investigated aspects and that more knowledge is acquired as people get older. These findings can support the development of appropriate and effective public health policies directed to this population and the dissemination of correct information about the event and its consequences.
\end{abstract}

Keywords: lead poisoning, children, parents.

\section{Percepción del riesgo de personas envueltas en intoxicación por plomo}

\begin{abstract}
Resumen: El objetivo de este estudio fue verificar la forma en que niños y sus responsables tienen sobre la intoxicación por plomo, y que implicaciones relatan sobre este hecho. Participaron 50 niños intoxicados de ambos sexos con edades comprendidas entre 4 y 13 años, sus progenitores y/o responsables. Los participantes respondieron en las entrevistas estructuradas, las que se buscabam mayor conocimiento sobre el plomo y su forma de intoxicación, sus efectos en el organismo infantil, posibles alteraciones en el ambiente en función de la contaminación, y qué, según los adultos, podría mejorar el desarrollo de los niños intoxicados. Los resultados indicaron la falta de comprensión de varios aspectos investigados, y la evolución del conocimiento con el aumento de la edad. Tales datos podrían subsidiar la propuesta de políticas de salud pública adecuadas y efectivas para la atención a esta población, así como en la divulgación de informaciones correctas sobre lo ocurrido en sus desdoblamientos.
\end{abstract}

Palabras claves: intoxicación por plomo, niños, padres.

Atualmente, devido às inúmeras atividades industriais, o chumbo se tornou uns dos contaminantes mais comuns do ambiente. Bellinger e cols. (2005), por exemplo, alertam que o maior problema de saúde pública na Índia é a exposição de crianças ao chumbo e, autores como Sterling e cols. (2004) enfatizam que esse também o é nos EUA,

1 Apoio: FAPESP. Esse texto foi revisado seguindo o Acordo Ortográfico da Língua Portuguesa (1990), em vigor a partir de $1^{\circ}$ de janeiro de 2009.

2 Endereço para correspondência:

Prof ${ }^{a}$ Dr $^{\mathrm{a}}$ Lígia Ebner Melchiori. Universidade Estadual Paulista Júlio de Mesquita Filho. Faculdade de Ciências (UNESP). Departamento de Psicologia. Campus de Bauru. Av. Eng. Luiz Edmundo C. Coube, 14-01. CEP: 17.033-360. Bauru-SP. Brasil. E-mail: lmelch@fc.unesp.br. embora esteja em declínio, nacionalmente, desde a retirada do chumbo da gasolina.

O nível de chumbo no sangue considerado como neurotóxico em crianças, pelo Centro de Prevenção e Controle de Doenças dos EUA, é de $10 \mu \mathrm{g} / \mathrm{dL}$ (Centers for Disease Control and Prevention, 2003). Porém, autores como Needleman e Bellinger (2001), entre outros, acreditam que não há nível seguro de exposição ao chumbo, visto que esse metal não possui nenhuma função fisiológica conhecida no organismo.

A Agência de Proteção Ambiental norte-americana (Environmental Protection Agency, 2009) nos alerta que o chumbo pode estar em qualquer lugar da casa: na pintura de paredes, nos móveis, nos brinquedos, em jornais ou revistas 
coloridos, no pó dos móveis, no chão e nos objetos, ao redor das janelas, em embalagens de alimentos, em alguns suplementos de cálcio, em encanamentos velhos, soldas, torneira. Quanto mais a água permanece em contato com o encanamento, mais oportunidade existe para contaminá-la, sendo assim, em instalações em que a água fica sem utilização por um período prolongado, como em escolas e creches, pode haver elevada concentração de chumbo.

De acordo com o setor de Exposição Humana ao Chumbo da Organização Mundial de Saúde (Human Exposure to Lead - World Health Organization - WHO), conforme citado por Freitas (2002), a exposição humana ao chumbo pode ocorrer por várias fontes: solo, ar, água e a ingestão sob diversas formas. Essa contaminação, embora possa ocorrer com maior intensidade em regiões específicas, esporadicamente, traz consequências extremamente graves à população afetada, sendo que o contato humano direto com esse metal pode causar distúrbios em praticamente todas as partes do organismo (Bellinger e cols., 2005). Seus efeitos podem alterar o sistema neurológico, causando déficits no sistema nervoso central e periférico (Rubens, Logina, Kravale, Eglite, \& Donaghy, 2001); no sistema renal (Moreira \& Moreira, 2004); no sistema hematológico, causando a inibição da síntese da hemoglobina (Saryan \& Zenz, 1994); no sistema endocrinológico, interferindo na conversão da vitamina $\mathrm{D}$ (Moreira \& Moreira, 2004); no desenvolvimento fetal, seja por seu efeito teratogênico (Freitas, 2002) ou por causar baixo peso e prematuridade (Moreira \& Moreira, 2004); pode causar alterações no comportamento, como a disfunção da percepção sensório-motora e a hiperatividade (Kahn, Kelly, \& Walter, 1995), podem diminuir a capacidade intelectual (Amaral, 2004; Kaufman, 2001) e essas alterações podem estender-se para problemas de atenção, aprendizagem, memória e rendimento escolar (Capellini, Rodrigues, Melchiori, \& Valle, 2008; Davis, Chang, Burns, Robinson, \& Dossett, 2004; Needleman \& Bellinger, 2001).

A maior sensibilidade das crianças aos efeitos da exposição ao chumbo ocorre porque: (a) o consumo por quilo de peso é maior do que nos adultos; (b) a absorção do chumbo pelo organismo da criança também é maior do que pelo dos adultos; (c) alguns comportamentos das crianças pequenas propiciam o maior contato com o chumbo como, por exemplo, levar objetos à boca; (d) crianças estão em desenvolvimento rápido e constante, tornando-se mais vulneráveis aos efeitos do chumbo (Yule \& Lannsdown, 1993).

Uma linha de pesquisa nessa área refere-se a medidas que podem ser adotadas para diminuir a contaminação do ambiente. Vários autores identificaram que, nas residências da zona urbana, a exposição ao pó contaminado por chumbo é a maior fonte de contaminação em crianças (Lamphear \& Roghmann, 1997; Sterling e cols., 2004). Campbell, Schwarz, Rich e Dockery (2003) conduziram um estudo na Filadélfia com 159 crianças, medindo-lhes o nível de chumbo no sangue e introduzindo a limpeza profissional nas casas de 73 delas. Essa limpeza reduziu imediatamente os níveis de chumbo na poeira, no entanto, logo o pó estava novamente contaminado.
Esses autores concluem que é necessário repetir frequentemente a limpeza nas residências, se o nível de chumbo no sangue precisa ser reduzido. A higiene sistemática e constante das casas pode ser mais importante na diminuição do chumbo no sangue das crianças do que uma limpeza profissional ocasional.

Também se encontram na literatura vários estudos que mostram a influência da intoxicação por chumbo na diminuição do Quoeficiente Intelectual - QI (Amaral, 2004; Canfield \& cols., 2003; Rodrigues, Almeida, \& Ribeiro, 2003; Kaufman, 2001). Canfield e cols. (2003) avaliaram o desenvolvimento intelectual de 172 crianças entre três e cinco anos e concluíram que há uma queda de 4,6 pontos no QI a cada $10 \mu \mathrm{g} / \mathrm{dl}$ de chumbo no sangue. Rodrigues e Carnier (2007) avaliaram o desenvolvimento de 60 crianças até cinco anos de idade contaminadas por chumbo, utilizando o Inventário Portage Operacionalizado. Os resultados apontaram defasagens importantes nas áreas de Cognição e Linguagem. Observou-se ainda, que os resultados em Cognição pioram à medida que aumenta a idade das crianças.

Em recente estudo, Ribeiro (2007) procurou investigar o efeito de duas intervenções domiciliares diferentes, em crianças de três a cinco anos contaminadas por chumbo: (a) uma em que as mães foram treinadas individualmente para lidar com os comportamentos em que seus filhos apresentavam déficits de desenvolvimento; (b) outra em que as crianças recebiam um brinquedo novo semanalmente e eram ensinadas a como utilizá-lo, tendo também a possibilidade de desenvolver comportamentos identificados como deficientes. Os dados indicaram que o maior acréscimo de comportamentos ocorreu no grupo em que as mães foram treinadas para estimular os comportamentos em déficit dos filhos. Outra conclusão foi a de que os déficits comportamentais tendem a se ampliar, ao longo do tempo, em população do tipo estudado, isto é, com baixa renda, baixo nível de escolaridade dos genitores, com profissões que exigem pouca qualificação e, ainda, contaminada por chumbo. Esses dados ilustram a importância de se proporcionar melhor ambiente à criança que, mesmo contaminada em um grau médio ou leve e vivendo em condições desfavoráveis, pode apresentar um desenvolvimento mais adequado.

Esses estudos parecem indicar que o combate a todas as formas de contato com o chumbo, principalmente em relação à limpeza doméstica diária e a estimulação cotidiana no ambiente familiar a que as crianças estão expostas, são condições fundamentais para a minimização dos seus efeitos no organismo e para o desenvolvimento infantil.

Os estudos anteriores também mostraram alguns dos possíveis efeitos de um evento ambiental sobre o desenvolvimento infantil e desempenho escolar. Embora a abordagem bioecológica de desenvolvimento humano, proposta por Bronfenbrenner (1979/1996), não tenha considerado explicitamente o binômio saúde/doença, ela fornece uma concepção que amplia a visão desse fenômeno (Morais \& Koller, 2004). Tendo como base essa abordagem, deve-se considerar a saúde nos mais diferentes contextos, que vão dos mais 
imediatos até os mais remotos. Dentro dessa perspectiva, é importante conhecer como um evento ambiental - a intoxicação por chumbo - vem influenciando crianças e adultos que vivenciam essa situação, como eles a percebem e explicam e, o que tentam fazer para manter as condições de saúde. Dessen e Guedea (2005), descrevendo a abordagem do curso da vida, destacam que seus princípios paradigmáticos geram temas que precisam ser considerados: "o entrelaçamento das vidas humanas e as mudanças históricas e ambientais; as organizações humanas e as tomadas de decisões e as restrições sociais; o senso de oportunidades das vidas e, por fim, as vidas em relação" (p. 15). Eventos ambientais que podem trazer alterações no desenvolvimento humano precisam ser estudados e, suas consequências, minimizadas ou superadas, exigindo que medidas sejam tomadas em nível individual e coletivo.

Todas essas considerações foram realizadas porque, em 2002, no interior de São Paulo, uma fábrica de baterias automotivas foi interditada. Após as avaliações, foram identificadas 316 crianças que estavam contaminadas por chumbo, em uma área superior a um $\mathrm{km}^{2} \mathrm{em}$ torno da fábrica. Constatouse que o nível de chumbo no sangue dessas crianças estava entre 10 e $90 \mu \mathrm{g} / \mathrm{dL}$. Verificou-se também a contaminação da fauna e da flora, resultando em enorme prejuízo para a população. Tomita e Padula (2005) descreveram os acontecimentos a partir do discurso da imprensa. Nesse bairro contaminado, a Secretaria Municipal de Saúde coordenou a limpeza e vedação de caixas d'água e a aspiração de frestas e arestas de portas e janelas de 164 casas. Foram também raspados cinco centímetros do solo de três residências de terra batida, dos quintais, das calçadas e de 80 ruas. Os moradores foram orientados a sacrificarem galinhas, patos, gansos e a não consumirem verduras rasteiras, ovos e leite caprino ou bovino (Farias, 2004).

Frente a essa situação de intoxicação por chumbo em crianças, e como o acontecimento está sendo assimilado na vida dos envolvidos, este estudo procurou dar voz a essas pessoas, crianças e adultos, para verificar como eles a estão compreendendo e vivenciando. Apesar de a doença ser um assunto que praticamente se limita à instituição médica e ao saber biomédico, ela é um fenômeno que ultrapassa esses limites, pois the são atribuídos diferentes significados, por indivíduos ou grupo sociais, uma vez que estar doente, ser hospitalizado ou ter sido exposto a uma contaminação ambiental configura um evento que necessita ser explicado pelo indivíduo e por seus familiares (Crepaldi, 1998).

O objetivo geral é o de avaliar a percepção de risco que as crianças contaminadas por chumbo e os adultos responsáveis por elas têm sobre essa contaminação e quais as implicações decorrentes desse fato. Os objetivos específicos são identificar: (a) o conhecimento deles a respeito do que é o chumbo e de como ocorre a contaminação; (b) os efeitos que o chumbo pode causar no organismo infantil; (c) a percepção da criança a respeito de alterações no ambiente, em função da contaminação por chumbo e o que os adultos têm a dizer a esse respeito e (d) o que os adultos julgam que poderia melhorar o desenvolvimento de suas crianças.

\section{Método}

\section{Participantes}

Participaram deste estudo 50 crianças contaminadas por chumbo, com idade de quatro a 13 anos e 50 genitores e/ou responsáveis por elas, $56 \%$ das crianças era do sexo masculino e, $44 \%$ do sexo feminino.

Optou-se por dividir as crianças em três grupos, de acordo com a faixa etária, para facilitar uma análise mais minuciosa dos resultados. O critério para essa divisão foi baseado no conteúdo semelhante das respostas obtidas dos participantes de idades próximas.

$\mathrm{Na}$ faixa etária de quatro a seis anos, participaram 19 crianças, oito do sexo feminino e 11 do masculino. O nível de chumbo desse grupo variou entre $10 \mu \mathrm{g} / \mathrm{dl}$ a $45,40 \mu \mathrm{g} /$ dl. Na faixa etária entre sete e nove anos, participaram 16 crianças, sendo oito do sexo feminino e oito do masculino, com nível de chumbo de $10,20 \mu \mathrm{g} / \mathrm{dl}$ a $27,30 \mu \mathrm{g} / \mathrm{dl}$. Na faixa etária de dez a 13 anos participaram 15 crianças, sendo seis meninas e nove meninos com nível de chumbo entre 10,10 $\mu \mathrm{g} / \mathrm{dl}$ a $40,30 \mu \mathrm{g} / \mathrm{dl}$. Com exceção de $36 \%$ das crianças de menor faixa etária, as demais frequentavam escola (da préescola ao $6^{\circ}$ ano do ensino fundamental). Dos participantes adultos, $88 \%$ eram do sexo feminino e $12 \%$ do masculino, com idade média de 33 anos (21-55 anos), sendo que 66\% frequentou do $4^{\circ}$ ao $8^{\circ}$ ano, $20 \%$ parou de estudar nos anos iniciais, $10 \%$ terminou o ensino médio e $4 \%$ nunca frequentou escola. Quase metade trabalhava no lar (48\%) ou como doméstica remunerada (18\%). Os demais trabalhavam no comércio, em fábricas, serviços gerais, manicura, costureiras, funcionário público e vigilante. Todos os participantes eram de classe sócio-econômica baixa, com renda familiar de um a três salários mínimos.

\section{Instrumentos}

Utilizou-se de um Roteiro de Anamnese sobre a criança e sua família subdividido em sete itens: dados de identificação; dados sobre a família e estruturação familiar; condições de moradia; desenvolvimento da criança; condições de gestação; escolaridade e relacionamento familiar.

A entrevista estruturada com as crianças e adultos se referiu à formulação de definições e/ou explicações a respeito do que é o chumbo, o que é a contaminação por chumbo, como ela pode ocorrer, seus efeitos e se houve alterações e/ ou percepção delas na rotina da casa em função do diagnóstico. Nos adultos, foi incluída a investigação a respeito do que eles julgam que poderia ser feito para melhorar o desenvolvimento das crianças contaminadas.

\section{Procedimento}

A coleta de dados teve duração de sete meses. As entrevistas foram realizadas em um Centro de Psicologia de 
uma universidade pública e na residência dos participantes, de acordo com a facilidade em realizá-las.

Aos genitores ou responsáveis por essas crianças, explicaram-se os objetivos do estudo, a importância da sua presença enquanto mediadores e informantes e a garantia da preservação de suas identidades. A seguir procedeu-se à leitura do Termo de Consentimento Livre e Esclarecido e, após sua concordância, o genitor ou responsável respondeu as perguntas referentes aos dados gerais da anamnese no roteiro elaborado da entrevista. As crianças foram entrevistadas em seguida. Todas as entrevistas realizadas foram gravadas e transcritas na íntegra.

\section{Análise de dados}

Dados parciais da anamnese foram utilizados para caracterizar a amostra desse estudo. Foi elaborado um sistema de categorias para análise das respostas obtidas e, a seguir, procedeu-se a quantificação. Os dados foram colocados em gráficos, nos quais considerou-se como $100 \%$ o total de respostas obtidas em cada pergunta dos participantes adultos e, como $100 \%$ o total de respostas obtidas em cada pergunta considerando-se cada uma das três faixas etárias das crianças.

\section{Resultados e Discussão}

Quando indagado sobre o que é o chumbo ("Você pode me explicar o que é chumbo?"), obtiveram-se 23 respostas na faixa etária de quatro a seis anos, 19 na de sete a nove anos, 18 na de dez a 13 anos e 88 na dos adultos. Esses dados podem ser vistos na Figura 1, distribuídos em sete categorias: (a) indefinida, quando o entrevistado não respondeu a pergunta ou disse que não sabia (Meu pai trabalha lá e não tem mais nada; Ah não sei, não sei quase nada); (b) descrição do conceito, quando havia tentativas de descrever o que é o chumbo, independentemente da resposta estar correta ou não; (c) local do ambiente, quando as respostas indicavam onde o chumbo pode ser encontrado no ambiente: terra, ar, água; (d) doença/exame, quando havia referência a doenças ou exames realizados para detectar a contaminação por chumbo (Quando alguém está com chumbo tem que ir no hospital, Chumbo é uma doença que tem no Tangarás [bairro próximo da fábrica de baterias]); (e) intrínseco ao organismo, quando se referiam a algo que passa a fazer parte do organismo ou que todo mundo tem (Parece que todo ser humano tem uma quantia no sangue); (f) descrição das consequências, quando apontavam as consequências nocivas da contaminação por chumbo ao desenvolvimento, bem como à saúde, com possibilidade de causar morte (Pode morrer, Eu sei que pode afetar o desenvolvimento da criança); (g) medidas de prevenção, quando explicavam o que precisava ser feito para evitar a contaminação ou minimizá-la (Não pode ficar descalço com o pé no chão).

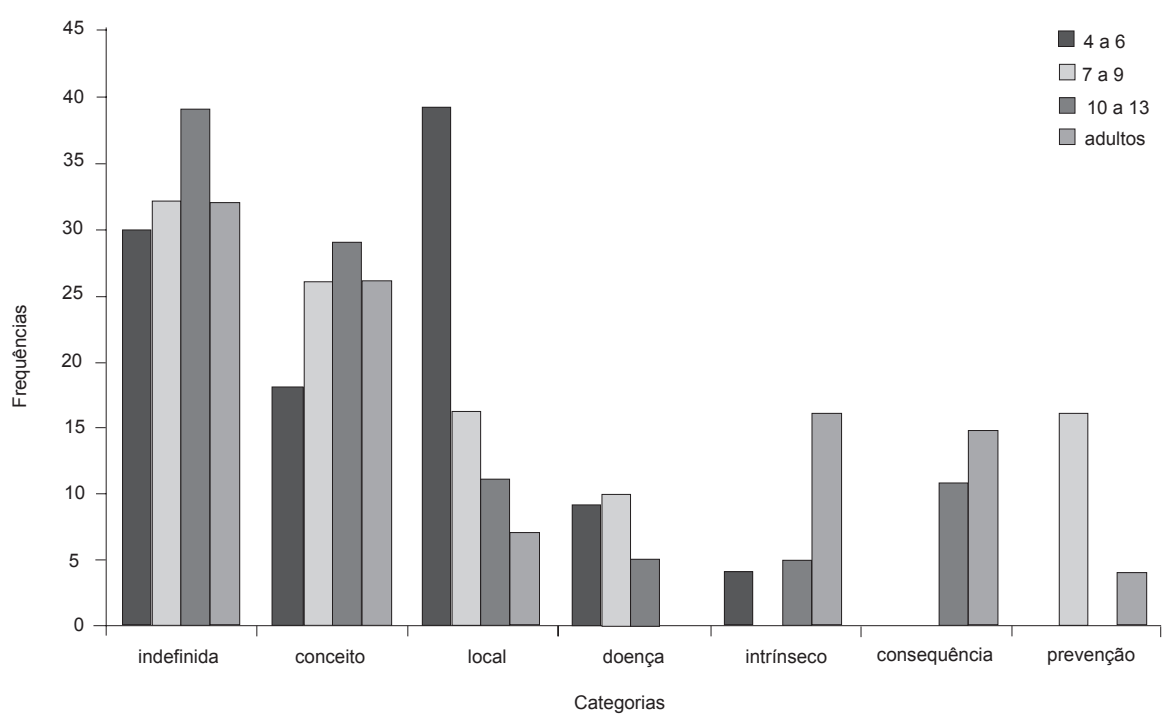

Figura 1. Percentual de respostas de crianças de três faixas etárias e de adultos a respeito da definição de chumbo.

Pode-se verificar que as três primeiras categorias que aparecem no gráfico ocorreram em todas as faixas etárias. A categoria indefinida foi a que mais se destacou em quase todas as faixas etárias, indicando que nem os adultos estão seguros do que é o chumbo.

Na categoria conceito, podem-se observar as tentativas de definição em todas as faixas etárias, sendo um pouco menor na faixa de quatro a seis anos. O que variou aqui foram as respostas. Na faixa etária menor, as respostas foram do tipo
É um verme; É o apelido da alface; É o bicho do gato. De sete a nove anos, as respostas foram do tipo Chumbo é uma bolinha pretinha; É aquele negocinho assim, é cinzinha. De dez a 13 anos e na faixa dos adultos as respostas foram semelhantes: Chumbo é um ferro; É um metal; É uma composição que é derretida né, e vira o chumbo.

A categoria local do ambiente, foi a mais mencionada pelas crianças menores, principalmente em relação à terra: Chumbo é o negócio que fica na terra. Crianças de sete a nove 
anos também tentaram definir o chumbo como algo que está na terra Chumbo é quando você brinca na terra e pega chumbo. Já as crianças maiores e os adultos diversificaram mais o local onde o chumbo pode ser encontrado: terra, ar e água.

Quando se investigou como pode ocorrer a contaminação por chumbo (Como uma pessoa pode se contaminar por chumbo?), obtiveram-se 22 respostas na faixa etária de quatro a seis anos, 26 na de sete a nove anos, 36 na de dez a 13 anos e 109 respostas dos adultos. Esses dados encontram-se na Figura 2, distribuídos em sete categorias, especificando as fontes que eles julgam como contaminadoras do ambiente: terra; ar; água; bateria automotiva ou pilha; animais; maquiagem e/ou qualquer tipo de tinta. Houve também respostas categorizadas como indefinida, quando afirmavam que não sabiam, ou outras que não respondiam à pergunta formulada.

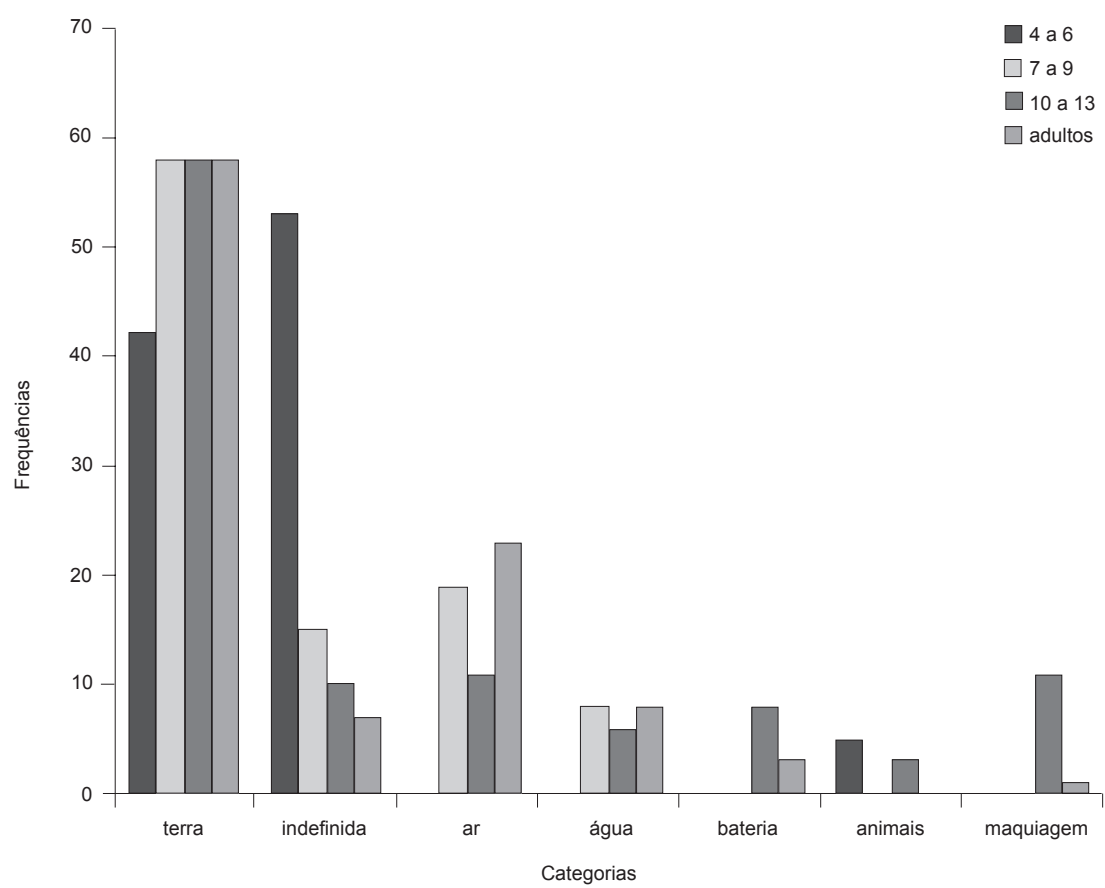

Figura 2. Percentual de respostas de crianças e adultos envolvidos com a contaminação por chumbo a respeito de como pode ocorrer a contaminação.

Em relação ao entendimento de como ocorre a contaminação por chumbo, pôde-se verificar que a categoria mais presente, em todas as faixas etárias, foi a de que ela ocorre por meio do contato com a terra (Porque pega na terra; Pega no brinquedo sujo). Pôde-se observar também um grande percentual de respostas indefinidas, principalmente na faixa etária menor (Não sei; Perguntou pra pessoa errada), apesar de estar presente em todas as idades.

A contaminação pelo ar e água foi citada pelas faixas etárias de sete anos para cima. Observou-se maior variabilidade de respostas na faixa etária de dez a 13 anos, pois além de citarem a terra (58\%), o ar (11\%) e a água (6\%) como possíveis formas de contaminação por chumbo, incluíram outras categorias como a criação de animais nas proximidades da área contaminada por chumbo (Até mesmo pelos animais que vivem lá), a relação entre contaminação e baterias automotivas (Pegando a bateria, a água da bateria) e respostas que indicavam que produtos de maquiagem e tintura de cabelo podem ser agentes de contaminação (Passando esmalte e pintando o cabelo, se maquiando, passando batom) com $11 \%$.

Com relação ao que pode acontecer a uma criança que foi contaminada por chumbo ( $O$ que pode acontecer com uma criança que foi contaminada por chumbo?), obteve-se, nas faixas etárias de quatro a seis anos, sete a nove anos e dez a 13 anos, o seguinte número de respostas: 20; 17 e 26 respectivamente. Foram definidas duas categorias: (a) doença, quando as respostas se referiam a ficar doente, procedimentos médicos, internações ou mesmo a morte; (b) indefinida, quando diziam não saber responder. Obteve-se o maior percentual de respostas indefinidas na faixa etária de quatro a seis anos (55\%). No entanto, os percentuais de respostas que se referiam à doença foram altos para as demais faixas etárias (de 79 a 83\%), indicando que predominam as respostas que se referem à doença e seus correlatos nessas faixas etárias. Já o conteúdo dessas respostas foi semelhante em todas as idades (Ela vai ser internada; Tem que ir no hospital tomar soro; Ele tem que ir tirar sangue; Pode ficar aleijada, pode perder a memória; Pode ficar gravemente doente; Pode morrer).

As respostas dos adultos foram mais específicas, citando desde sintomas como dor de cabeça, até alterações no comportamento como a desatenção. Foram obtidas 81 respostas, divididas em 12 categorias, cujo maior percentual foi $20 \%$. A categoria mais frequente foi saúde em geral 
(20\%), quando afirmavam que o chumbo afetava a saúde da criança sem especificarem quais os problemas decorrentes (Dá problema de saúde; Já tem casos graves, de ficar internada a criança). Em segundo lugar, com 17\%, ocorreu a categoria de respostas indefinidas, quando os adultos não souberam responder ou suas respostas foram evasivas, não respondendo ao que foi perguntado (Ah! Ele brinca muito na terra porque não tem como evitar de brincar na terra por mais que o quintal seja cimentado; Não sei dizer). As categorias de respostas que vieram a seguir, com percentuais em ordem decrescente foi a agressivalagitada, quando se referiam a comportamentos da criança que expressa nervosismo, agitação, agressividade, com 12\% (Agressivo dentro de casa... e falaram que é por causa do chumbo); a sistema ósteo-muscular, quando as respostas envolviam ossos e músculos em geral (Pelos ossos; Ele anda caindo muito e o pessoal lá do Centrinho disse que ele poderia cair muito); e sistema psíquico, quando envolvia respostas que especificam problema emocional ou psicológico (Emocional né; Acho que no desenvolvimento psicológico), com 11\% de respostas em cada categoria. Das respostas, 10\% foram categorizadas como sistema neurológico, quando se referiam ao funcionamento do cérebro e nervos periféricos (Ah! Diz que afeta o cérebro, né? Porque a minha menina tinha muita dor de cabeça). A categoria dificuldade escolar, ocorreu em $8 \%$ das respostas, quando julgavam que o chumbo podia prejudicar o desempenho acadêmico dos filhos (Eu acho que ele não consegue passar de ano, ele tava indo bem, mas depois de repente ele começou a não conciliar, não aprendeu a ler até agora"). A essas categorias, seguiram-se outras com percentuais inferiores ainda, categorizadas como desatenta/ lenta (quando envolvia uma classe de respostas que incluía comportamentos que indicavam que a criança estava mais lenta, e/ou esquecida e/ou desatenta: ela ficou meio esquecida, desligada, e eu acho que pode ser do chumbo; fica uma pessoa mais parada, mais longe das coisas, sem interesse em mais nada) e outras (quando as respostas envolviam o sistema digestivo, urinário, o hematológico ou respiratório: Até hoje, a gente leva ele no dentista, porque os dentes dele ficaram bem amarelos, bem fracos; que nem o pai dele, que quando trabalhava na fábrica, que atacou o fígado; Tem uns que dá problema nos rins; Olha, começa pela respiração).

Também se investigou se houve alguma alteração na rotina diária da casa da criança, depois que se tomou conhecimento da contaminação por chumbo (Houve alguma alteração na sua casa depois que começou a se falar da contaminação por chumbo?). Foram obtidas 19 respostas na faixa etária de quatro a seis anos, 16 na de sete a nove anos, 19 na de dez a 13 anos e 66 respostas dos adultos. Foram definidas seis categorias: (a) geral, incluindo as respostas indicando que houve alterações, sem especificá-las (Sim, não sei); (b) conduta, quando as respostas eram para afirmar que houve alterações no ambiente familiar, principalmente, em relação às proibições ou condutas de higiene (Não brincar na terra; falando para eles lavar as mãos); (c) ambiente físico, inclui as respostas relacionadas a ações que resultaram em mudanças na habitação interna e/ou externa (Eu cuido mais principalmente da limpeza da casa porque eles não podem com poeira e a gente sabe que tá tudo contaminado; Minha mãe tirou a horta do quintal); (d) intervenção no bairro/condução, quando as respostas citaram mudanças ocorridas no bairro ou indicaram o meio de condução para fazer as avaliações e acompanhamentos (Veio um homem aqui, tinha chumbo na grama e mandou tirar a grama; Eles rasparam o chão em $5 \mathrm{~cm}$ ); (e) mudança alimentar refere-se a não comprar alimentos do bairro nem ingeri-los sem lavar e não plantá-los. Não comprar mais leite das vacas criadas ali, tomar mais cuidado com a água de beber e melhorar a qualidade da alimentação; (f) negativa, quando relatavam não ter ocorrido nenhum tipo de mudança no ambiente familiar após a identificação da contaminação por chumbo (Não, a mesma coisa); (g) indefinida, incluem-se as respostas em que não havia indicação se houve ou não mudanças na rotina diária da família, após a constatação da contaminação ambiental (Nem sei), ou não responderam exatamente ao que foi perguntado. A Tabela 1 apresenta esses dados.

Tabela 1. Percentual de categorias de respostas de crianças e adultos envolvidos com a contaminação por chumbo a respeito de possíveis alterações na rotina diária familiar.

\begin{tabular}{lcccc}
\hline \multicolumn{1}{c}{ Categorias } & $\begin{array}{c}\text { 4 a 6 } \\
\text { anos (\%) }\end{array}$ & $\begin{array}{c}7 \text { a 9 } \\
\text { anos (\%) }\end{array}$ & $\begin{array}{c}\text { 10 a 13 } \\
\text { anos (\%) }\end{array}$ & Adultos (\%) \\
\hline Geral & 12 & 14 & - & - \\
$\begin{array}{l}\text { Conduta } \\
\text { Ambiente }\end{array}$ & 4 & 25 & 26 & 26 \\
físico & - & 5 & 16 & - \\
$\begin{array}{l}\text { Intervenção } \\
\text { bairro }\end{array}$ & - & - & 16 & 21 \\
$\begin{array}{l}\text { Mudança } \\
\text { alimentar }\end{array}$ & - & - & - & 21 \\
$\begin{array}{l}\text { Negativa } \\
\text { Indefinida }\end{array}$ & 68 & 51 & 42 & 30 \\
\hline & 16 & 5 & - & 2 \\
\hline
\end{tabular}

A categoria de respostas que predominou em todas as faixas etárias foi a da resposta negativa, com $68 \%$ na faixa de quatro a seis anos, decrescendo até 30\% nos adultos, indicando que há maior percepção das alterações realizadas ou de sua negação, com o aumento da idade. A categoria de respostas que se destaca a seguir, na maior parte das faixas etárias, é a da conduta, indicando a percepção do aumento das proibições e cuidados com a higiene de sete a 13 anos, compatíveis com a declaração de maior exigência nesses itens pelos adultos (Eu acho que não podia mais sair na rua; Então eu diminui isso, não deixei mais ele brincar na terra, porque criança brinca na terra, coloca a mão na boca, não tem cuidado). Alterações na alimentação das crianças só foram relatadas pelos adultos (Não compro mais verdura aí [no bairro]; Eu só parei de dar leite, que eu dava leite comprado lá no T. [ bairro], única coisa; Mudou bastante. A parte 
de frutas, a alimentação, alimenta bem, toma bastante leite porque é bom) e a percepção de alterações no ambiente fisicico foi mais identificada pelas crianças mais velhas e adultos (Só mudou a limpeza da caixa d'água; Mudou, fizemos até um cimentado no quintal em função das crianças). Apenas as crianças de dez a 13 anos descreveram as alterações ocorridas no bairro. A categoria geral, sem especificação de quais foram as alterações (Mudou umas coisas aqui, na história do chumbo que está sarando já), apareceu apenas nas faixas etárias de quatro a nove anos, indicando que, com o amadurecimento, essas respostas diminuem. Já a categoria indefinida ocorreu com maior percentual com as crianças menores (Faz tempo que eu comi chumbo; Houve. Porque ela estava lá, ela pegava as bonecas e começava a se despedir, né. Falava: - Mamãe vai morrer, filha),

Também foi investigado o que os adultos achavam que poderia ser feito para melhorar o desenvolvimento de suas crianças contaminadas $(O$ que você acha que poderia ser feito para melhorar [ainda mais] o desenvolvimento de seu(sua) filho(a)?), obtendo-se 56 respostas que foram classificadas em seis categorias. Trinta por cento das respostas se referiram à necessidade de exercer ações no bairro, como asfaltá-lo ou oferecer acesso a cursos e atividades recreativas (Eu acho que asfaltar a rua e fechar os terrenos vazio para não entrar criançada no terreno; Eu acho que o governo daqui deveria se empenhar mais em ajudar no desenvolvimento da criança, mais curso de computação, mais prática esportiva, desenvolver algum projeto nos bairros). As categorias que se referiam às ações diárias dos adultos com as crianças (Alimentação boa, dar uma boa alimentação; Eu converso bastante) e as respostas categorizadas como negativas, referindo-se a não saber responder ou achar que não é necessário fazer nada (Então, eu acho que não tem o que fazer mais, eu acho que se exagerou um pouco as coisas; Acho que agora não tem mais assim, já tá bem desenvolvido agora, passou por psicóloga, fono, tudo) obtiveram um percentual de $18 \%$.

Dezesseis por cento das respostas dos adultos foram categorizadas como indefinidas porque não sabiam responder (Gostaria, mas não sei como), seguidas das que indicavam a necessidade de continuidade do tratamento, com 13\% (Essas avaliações eu acho que vai ajudar também; pra melhorar ele poderia estar em contato com psicólogo porque eu acho que isso ajuda a melhorar bastante o desenvolvimento, né?). Cinco por cento das respostas indicaram a crença inatista subjacente, justificando que a criança muda de humor em função da fase do desenvolvimento (Eu espero que ele melhore quando crescer, que muitos falam que é por causa da idade, eu estou esperando ele crescer para melhorar).

Este estudo procurou compreender a percepção que as crianças intoxicadas por chumbo e os adultos responsáveis por elas têm sobre essa contaminação e quais as implicações decorrentes desse fato. Os adultos e crianças foram aqui incluídos porque, segundo Bronfenbrenner (1979/1996), ao limitar-se em focalizar apenas um deles, deixar-se-ia de considerar um importante aspecto do microssistema, que influencia diretamente a ambos.

Os dados indicaram que as crianças contaminadas por chumbo e os adultos responsáveis por elas pouco sabem sobre o que é chumbo. Na faixa etária das crianças mais novas, houve maior número de tentativas de definição do conceito chumbo, sendo que $39 \%$ das respostas o definiram como algo relacionado à terra (local). Acredita-se que essa relação se deu em função dessas crianças viverem em um bairro onde as ruas são de terra batida e habitualmente brincarem na terra dos quintais das casas, terrenos baldios ou ruas. Após constatar a contaminação por chumbo, elas foram proibidas de brincar nesses locais, o que pode ter contribuído para a elaboração da relação entre chumbo e terra. Observase também, que algumas crianças da faixa etária de quatro a seis anos definiram o conceito chumbo de forma incompreensível para os adultos, como por exemplo, o apelido da alface ou quando outra disse que chumbo é um verme, o que indica como as crianças apreendem de forma muito especial o mundo que as cerca.

Já na faixa etária dos sete anos em diante, a categoria mais citada em relação ao que é o chumbo foi a de respostas indefinidas. Nas respostas em que houve uma tentativa em definir o conceito de chumbo, pôde-se observar a dificuldade em dar uma definição real desse metal. Nesse sentido, enfatiza-se a importância do agente de saúde e do professor de educação infantil e ensino fundamental, enquanto mediadores do processo ensino-aprendizagem. Bronfenbrenner (1979/1996) enfatiza a presença desses agentes 'significativos' por serem pessoas do ambiente imediato, podendo atuar ativamente no desenvolvimento da criança com suas concepções e conhecimentos. Para tanto, é necessário que esses profissionais estejam preparados e envolvidos na problemática vivenciada por essas famílias.

A forma de contaminação mais conhecida pelas crianças de todas as faixas etárias e pelos adultos é a terra e/ou areia. No entanto, pôde-se observar que nas faixas etárias acima de sete anos, o conhecimento acerca de como uma pessoa pode se contaminar por chumbo aumenta, já que se observa maior variabilidade de respostas. Na faixa etária de dez anos em diante, o conhecimento aumenta ainda mais, pois além de citarem a terra, ar e água como formas possíveis para a contaminação por chumbo, eles incluíram também outras categorias. Esses dados estão de acordo com os encontrados na literatura, que indicam que o solo, ar, água e sua ingestão sob formas variadas, são fontes de exposição humana ao chumbo (dados do WHO - Human Exposure to Lead, conforme citado por Freitas, 2002). Freitas (2002) também destaca a utilização do chumbo como antidetonante de gasolina e produção de baterias para automóveis, além de diversos usos industriais, entre eles a produção de vários pigmentos largamente utilizados na indústria química, o que, de certa forma, foi explicitado pelos participantes de dez anos em diante.

A percepção que as crianças da amostra têm, principalmente as de sete a 13 anos, a respeito das consequências da 
contaminação por chumbo é a de ficar internada no hospital, apresentar vários sintomas, ficar aleijada, gravemente doente e até morrer. Alguns também citaram a necessidade de realizar exame de sangue. Crepaldi (1998) alertou que a criança se julga doente quando não tem vontade de brincar. É provável, pelas respostas obtidas, que as crianças da amostra sentiriam a maior gravidade da situação em que se encontram, se houvesse necessidade de internação ou por sentirem-se prostradas e, consequentemente, por não brincarem ou pela dificuldade em fazê-lo. Talvez fosse interessante ter perguntado diretamente a elas se sentiam algum sintoma e se se consideravam doentes. É importante acrescentar, também, que algumas crianças do bairro já foram internadas e uma chegou a falecer e, que esses acontecimentos provavelmente faziam parte das conversas cotidianas. Já os adultos apresentaram uma noção maior da variedade de consequências possíveis no organismo e comportamento das crianças.

Outro fator importante a ser destacado é o de que o entendimento da alteração da rotina em casa e no bairro, decorrentes da contaminação, aumenta com a idade. Esforços neste sentido são necessários para se conseguir a colaboração das crianças em evitar novas oportunidades de contaminação, uma vez que podem estar expostas ao contato com a terra, água não tratada, ingestão de água não fervida e filtrada, consumo de alimentos de origem animal e vegetal oriundos do bairro, dentre outros.

Os genitores ou responsáveis pelas crianças também necessitam ser instruídos a respeito de todos os cuidados necessários e sobre a forma de explicá-los às crianças, de acordo com seu nível de compreensão, sem ameaçar, mas expressando racionalmente as medidas necessárias, de forma que estas compreendam, uma vez que a contaminação é fato consumado e presente no seu cotidiano e de seus familiares. Os resultados indicaram que as ações remediativas adotadas pelos genitores ou responsáveis, após a identificação da intoxicação, não foram percebidas pela grande maioria das crianças como alterações na rotina diária.

Pôde-se verificar que os adultos também perceberam a necessidade de maior investimento no bairro, seja para fazer alterações físicas, dificultando às crianças o acesso a terra, ou para oferecer cursos e práticas esportivas que promovam o seu desenvolvimento. Isso aponta para a necessidade de políticas de saúde pública que realmente ajudem a população prejudicada, uma vez que são medidas que estão fora do alcance pessoal dos participantes do estudo. Bronfenbrenner (1979/1996) destaca que o exossistema não envolve a pessoa em desenvolvimento como participante ativo, mas pode influenciar de forma positiva, negativa ou neutra o microssistema. Medida como implantar no bairro cursos e práticas esportivas é exemplo de como o exossistema, no caso a prefeitura e suas secretarias, poderiam investir e melhorar a qualidade de vida da população alvo do estudo.

De modo geral, este estudo mostrou que: (a) a definição de chumbo é deficitária em todas as faixas etárias; (b) com o aumento da idade, aumenta o nível de compreensão da situação que estão vivenciando; (c) a forma de contaminação que parece ser mais conhecida em todas as faixas etárias é o contato com a terra ou areia; (d) as crianças maiores e os adultos conhecem maior número de formas de contaminação por chumbo; (e) a percepção que as crianças têm da contaminação por chumbo no organismo é a de ficar gravemente doente, sem especificação do tipo de problemas que ele pode causar no organismo, diferentemente dos adultos; (f) a compreensão da alteração da rotina, em casa ou no bairro, após a identificação da contaminação, é pequena, mas aumenta com a idade, ficando próxima das alterações que os adultos dizem ter realizado; ( $\mathrm{g}$ ) há um destaque da percepção dos genitores ou responsáveis pelas crianças de que algumas ações no bairro, que devem ser realizadas pelo poder público, contribuiriam com a promoção do desenvolvimento infantil.

Para que intervenções possam ocorrer com a população afetada, faz-se necessário um trabalho multidisciplinar, envolvendo profissionais de diversas áreas, tanto em relação à conscientização do problema, como em busca de soluções minimizadoras, inclusive com a utilização de agentes mediadores mais próximos das crianças e dos pais, como os professores das crianças e os agentes de saúde.

\section{Considerações finais}

Verificou-se neste estudo que, apesar de já terem sido noticiados casos de contaminação por chumbo no país, em geral oriundas de acidentes ambientais, a maioria da população não tem informações precisas sobre os riscos e as consequências do contágio por esse metal para a saúde humana. É um dever do setor de saúde do Município e do Estado, uma vez que não se justifica um descaso da área pública frente a um problema tão grave, fazer chegar informações mais claras e objetivas à população envolvida, cujo direito é legítimo. Morais e Koller (2004) destacam que a saúde resulta do processo de interação contínuo entre o indivíduo e o ambiente e que há necessidade de que cada contexto, desde o micro até o macro, exerça seu papel para garantir a proteção e a promoção da saúde. A abordagem bioecológica forneceu parâmetros para identificar como os variados contextos se integram e a importância de um esforço coletivo para a minimização e superação das dificuldades impostas.

Conhecer o que é o chumbo, qual o processo de sua contaminação no organismo, implicações para a saúde e, principalmente, como adotar medidas preventivas e/ou minimizadoras, é condição fundamental para a melhoria da qualidade de vida de uma parcela da população. Espera-se que os resultados desse estudo ofereçam subsídios para a melhoria da qualidade do atendimento a essa população e da proposição de políticas de saúde pública que realmente levem em consideração as pessoas e o meio ambiente envolvido. 


\section{Referências}

Amaral, J. N. (2004). Avaliação intelectual de crianças contaminadas por chumbo: Um estudo comparativo. Dissertação de Mestrado não-publicada, Unesp de Marília, Marília, SP.

Bellinger, D. C., Hu, H., Kalaniti, K., Thomas, N., Rajan, P., Sambandam, S., Ramaswamy, P., \& Balakrishnan, K. (2005). A pilot study of blood lead levels and neurobehavioral function in children living in Chennai, India. International Journal Occupational and Environmental Health, 11, 138-143.

Bronfenbrenner, U. (1996). A ecologia do desenvolvimento humano: Experimentos naturais e planejados. Porto Alegre: Artmed. (Original publicado em 1979)

Campbell, C., Schwarz, D. F., Rich, D., \& Dockery, D. W. (2003). Effect of a follow-up professional home cleaning on serial dust and blood lead levels of urban children. Archives of Environmental Health, 58, 771-780.

Canfield, R. L., Henderson, C. R. Jr., Cory-Slechta, D. A., Cox, C., Jusko, T. A., \& Lanpher, B. P. (2003). Intellectual impairment in children with blood lead concentrations below 10 microg per ceciliter. The New England Journal of Medicine, 348, 1517-1526.

Capellini, V. L. M. F., Rodrigues, O. M. P. R., Melchiori, L. E., \& Valle, T. G. M. (2008). Crianças contaminadas por chumbo: Estudo comparativo sobre desempenho escolar. Estudos em Avaliação Educacional, 19, 155-180.

Centers for Disease Control and Prevention. (2003). Children's blood levels in the United States. Departament of Health and Human Services. Recuperado em 25 outubro 2006, de http://www.cdc.gov/nceh/lead/research/ kidsBLL.htm

Crepaldi, M. A. (1998). Famílias de crianças acometidas por doenças crônicas: Representações sociais da doença. Paidéia (Ribeirão Preto), 8, 151-167.

Davis, D. W., Chang, F., Burns, B., Robinson, J., \& Dossett, D. (2004). Lead exposure and attention regulation in children living in poverty. Developmental Medicine \& Child Neurology, 46, 825-831.

Dessen, M. A., \& Guedea, M. T. D. (2005). A ciência do desenvolvimento humano: Ajustando o foco de análise. Paidéia (Ribeirão Preto), 15, 11-20.

Environmental Protection Agency. (2009). Lead Awareness Program, protect your child from lead poisoning. Recuperado em 08 maio 2009, de http://www.epa.gov/ opptintr/lead/index.html .

Farias, S. (2004, Março). Chumbo: O peso da contaminação. Jornal Contexto: Jornal-laboratório do curso de Jornalismo da Unesp, 20(5), p. 2.

Freitas, C. U. (2002). Estratégias de abordagem para a exposição ambiental ao chumbo no Estado de São Paulo. Recuperado em 17 fevereiro 2006, de http:/www.cve.saude.sp.gov.br/htm/doma/chumbo.htm
Kahn, C. A., Kelly, P. C., \& Walter, W. A. (1995). Lead screening in children with attention deficit hyperactivity disorder and development delay. Clinical Pediatrics, 34, 498.

Kaufman, A. S. (2001). How dangerous are low (not moderat or high) doses of lead for children's intellectual development? Archives of Clinical Neuropsychology, 16, 403-431.

Lamphear, D. P., \& Roghmann, K. J. (1997). Pathways of lead exposure in urban children. Environmental Research, 74, 67-73.

Morais, N. A., \& Koller, S. H. (2004). Abordagem ecológica do desenvolvimento humano, psicologia positiva e resiliência: Ênfase na saúde. In S. H. Koller (Org.), Ecologia do desenvolvimento humano: Pesquisa e intervenção no Brasil (pp. 91-107). São Paulo: Casa do Psicólogo.

Moreira, F. R., \& Moreira, J. C. (2004). Os efeitos do chumbo sobre o organismo humano e seu significado para a saúde. Revista Panamericana de Salúd Publica, 15, 119-128.

Needleman, H. L., \& Bellinger, D. (2001). Studies of lead exposure and the developing central nervous system: A reply to Kaufman. Archives of Clinical Neuropsychology, $16,359-374$.

Ribeiro, M. (2007). Efeito de diferentes intervenções domiciliares no repertório comportamental de crianças contaminadas por chumbo. Dissertação de Mestrado não- publicada, Universidade Federal de São Carlos, São Carlos, SP.

Rodrigues, O. M. P. R., Almeida, S. H., \& Ribeiro, T. M. (2003). Avaliação do desenvolvimento de crianças de um a três anos de idade contaminadas por chumbo. In C. M. B. Neme \& O. M. P. R. Rodrigues (Orgs.), Psicologia da saúde: Perspectivas interdisciplinares (pp. 73-94). São Carlos: Rima.

Rodrigues, O. M. P. R., \& Carnier, L. E. (2007). Avaliação do desenvolvimento geral de crianças de um a cinco anos de idade contaminadas por chumbo. Interação em Psicologia, 11, 269-279.

Rubens, O., Logina, I., Kravale, I., Eglite, M., \& Donaghy, M. (2001). Peripheral neuropathy in chronic occupation inorganic lead exposure: A clinical and eletrophysiolocil study. Journal of Neurology, Neurosurgery and Psychiatry, 71, 200-204.

Saryan, L. A., \& Zenz, C. (1994). Lead and its compounds. In C. Zenz, B. Dickerson, \& E. P. Horvath (Orgs.), Occupational medicine (pp. 506-541). St. Louis: MsbyYear Book.

Sterling, D. A., Evans, R. G., Shadel, B. N., Serrano, F., Arndt, B., Chen, J. J., \& Harris, L. (2004). Effectiveness of cleaning and health education in reducing childhood lead poisoning among children residing near superfund sites in Missouri. Archives of Environmental Health, 59, $121-131$ 
Tomita, N. E., \& Padula, N. A. M. R. (2005). Intoxicação por chumbo em crianças e o discurso da imprensa. Ciência \& Saúde Coletiva, 10(Sup), 111-119.

Yule, W., \& Lannsdown, R. G. (1993). Blood lead concentrations in school age children, intelligence and attainment in a school populations: A pilot study. Developmental Medicine and Child Neurologic, 23, 567-576.

Lígia Ebner Melchiori é Professora Doutora do Departamento de Psicologia da Faculdade de Ciências da Universidade Estadual Paulista Júlio de Mesquita Filho, campus Bauru.

Patrícia Kusumi é graduanda do Curso de Psicologia da Faculdade de Ciências da Universidade Estadual Paulista Júlio de Mesquita Filho, campus Bauru.

Olga Maria Piazentin Rolim Rodrigues é Professora Adjunta do Departamento de Psicologia da Faculdade de Ciências da Universidade Estadual Paulista Júlio de Mesquita Filho, campus Bauru.

Tânia Gracy do Valle é Professora Doutora do Departamento de Psicologia da Faculdade de Ciências da Universidade Estadual Paulista Júlio de Mesquita Filho, campus Bauru.

Vera Lúcia Messias Fialho Capellini é Professora Doutora do Departamento de Psicologia da Faculdade de Ciências da Universidade Estadual Paulista Júlio de Mesquita Filho, campus Bauru.

Carmem Maria Bueno Neme é Professora Adjunta do Departamento de Psicologia da Faculdade de Ciências da Universidade Estadual Paulista Júlio de Mesquita Filho, campus Bauru.

Recebido: 01/10/2008

$1^{a}$ revisão: 05/06/2009

$2^{a}$ revisão: 07/07/2009

Aceite final: 11/08/2009 